Holloway, B. W. (1955). J. gen. Microbiol. 13, 572-581

\title{
Genetic Recombination in Pseudomonas aeruginosa
}

\author{
By B. W. HOLLOWAY \\ Department of Microbiology, John Curtin School of Medical Research, Australian \\ National University, Canberra, Australia
}

\begin{abstract}
SUMMARY: Genetic recombination has been shown to occur in Pseudomonas aeruginosa. Crosses between 18 biochemical mutants of 4 strains were studied and, although non-random segregation was found for non-selective markers, it has not yet been possible to draw conclusions concerning gene order or linkage. The progeny obtained from crosses tended to resemble one parent more than the other. The 4 strains of $\boldsymbol{P}$. aeruginosa used were interfertile in certain combinations but selfsterile. There was no evidence for an infectious principle affecting fertility but fertility changes may occur amongst recombinant progeny.
\end{abstract}

Genetic studies in Escherichia coli have demonstrated a mechanism of genetic exchange which until now has been unique among bacteria (see Lederberg $\mathrm{et} \mathrm{al.,}$ 1951 ; Hayes, 1953). Even within this species practically all of the work has been restricted to the K12 strain. However, Cavalli \& Heslot (1949) found that the strain NCTC 123 was fertile with K12, but its complex growth requirements made further work difficult. By means of a screening method Lederberg (1951) tested 2000 strains of $E$. coli and found over 50 to be crossfertile with K12, and as far as was tested with each other. de Haan (1954) demonstrated recombination in $E$. coli strain B by transferring the $\mathbf{F}+$ character from $\mathrm{K} 12$ to $E$. coli $\mathrm{B}$. This strain had previously been thought to be infertile but is apparently $\mathbf{F}-$. These results suggested that this type of genetic mechanism may occur not only in other strains of $E$. coli but also in other species of bacteria and for this reason genetic studies were begun with Pseudomonas aeruginosa. This organism grows luxuriantly on the usual bacteriological media, and grows adequately on a chemically defined medium of glucose and mineral salts. It is of low pathogenicity and can be readily isolated from a variety of sources.

\section{METHODS}

\section{Bacterial strains}

A collection of strains of Pseudomonas aeruginosa was obtained, and after studying their general cultural behaviour the following were selected for further investigation.

Strain 1, isolated from a wound, Melbourne. This strain freely produces green pigment and grows luxuriantly on nutrient agar. It gives a dense turbidity in nutrient broth with a thin surface pellicle and is lysogenic for a bacteriophage which attacks strain $\mathrm{L}$.

Strain 3 was isolated from a wound at Melbourne. It grows readily on nutrient agar forming a scummy growth which does not readily emulsify and in nutrient broth it produces little turbidity but a well-developed pellicle. 
Pigment is produced sparingly. The strain is naturally resistant to streptomycin and is lysogenic for a bacteriophage which attacks strains 1 and $\mathrm{L}$.

Strain 29. This is a stock strain from the Department of Bacteriology, University of Adelaide. It produces pigment sparingly, grows readily on nutrient agar and produces a dense turbidity in nutrient broth with little pellicle formation. It is lysogenic for a phage attacking strain $\mathrm{L}$.

Strain $L$. This is strain LIII-3bi isolated by Don \& van den Ende (1950). It has a slower growth rate than the other three strains. In nutrient broth a poorly developed pellicle is formed. This strain does not produce pigment. It is sensitive to bacteriophages carried lysogenically by strains 1,3 and 29 .

Stock cultures were maintained on nutrient agar slopes at $4^{\circ}$ from which subcultures to nutrient broth were made as required. A duplicate set of slopes was kept at $-15^{\circ}$.

\section{Media}

Complete medium. Difco nutrient broth and agar with the addition of $0.5 \%$ Difco yeast extract. Pigment production on this medium was enhanced by the addition of $1 \%(\mathrm{w} / \mathrm{v})$ glycerol.

Minimal medium. The medium ascribed to B. D. Davis by Lederberg (1950) was used. This is composed as follows: glucose, $1 \mathrm{~g}$., dipotassium hydrogen phosphate, 7 g.; potassium dihydrogen phosphate, 2 g.; sodium citrate $\left(5 \mathrm{H}_{2} \mathrm{O}\right)$, $0.5 \mathrm{~g}$.; magnesium sulphate $\left(7 \mathrm{H}_{2} \mathrm{O}\right), 0 \cdot 1 \mathrm{~g}$.; ammonium sulphate $1 \mathrm{~g}$.; water 1 l.; agar (when required) $15 \mathrm{~g}$.

\section{Mutants}

Nutritionally-deficient mutants for a variety of amino acids and purines were obtained by combination and appropriate modifications of the various techniques used by Demerec (1951), Davis (1948), Loutit (1952) and Lederberg \& Lederberg (1952). The procedure was as follows.

The parent strain was inoculated into complete broth and grown with agitation at $37^{\circ}$ for $24 \mathrm{hr}$. The culture obtained was centrifuged and resuspended in $0.3 \mathrm{M}$-sodium chloride for $60 \mathrm{~min}$. at $37^{\circ}$. The suspension was centrifuged again and the organisms resuspended in $0.04 \%$ manganous chloride for $60 \mathrm{~min}$. at $37^{\circ}$. After further centrifugation the packed organisms were inoculated into a fresh tube of nutrient broth which was then incubated with shaking at $37^{\circ}$ for $18 \mathrm{hr}$. The bacteria from this growth were centrifuged, washed twice in saline, and finally suspended at a concentration of $10^{7}$ organisms $/ \mathrm{ml}$. in minimal medium without ammonium sulphate and kept at $37^{\circ}$ for $4-6 \mathrm{hr}$. without shaking. At the end of this period the suspension was centrifuged, the organisms resuspended to a concentration of $10^{6} / \mathrm{ml}$. in minimal medium + 15,000 units penicillin $/ \mathrm{ml}$. and incubated with shaking overnight at $37^{\circ}$. Sufficient penicillinase was then added to inactivate most of the penicillin, the culture being kept at $37^{\circ}$ for $1 \mathrm{hr}$. to enable the enzyme action to take place. Dilutions of this culture $(1 / 10,1 / 100,1 / 1000)$ were made in saline and $0 \cdot 1 \mathrm{ml}$. samples of these dilutions plated on complete agar and incubated overnight. Selecting plates with a suitable colony density. replica plates on minimal agar 
were made, using the velveteen pad technique, and after overnight growth the replicas were compared with the nutrient plates. Any colonies which appeared on the nutrient plates but not on the minimal plates were subcultured and examined further. Identification of the specific growth requirements of the various mutants was made using the methods described by Lederberg (1950).

The frequency of recovery of mutants varied between $0 \cdot 1$ and $1 \%$ and differed from strain to strain. The various mutant requirements obtained are shown in Table 1. A number of mutants fell into the 'unknown' class, growth occurring with yeast extract but not with any single amino acid, vitamin, purine or pyrimidine, nor with any tested mixture of these substances. These mutants were not further investigated. The various mutants are referred to by the parent strain number or letter followed, in brackets, by the symbol for the biochemical requirement as given in Table 1 .

Table 1. Biochemical mutants obtained by treatment of Pseudomonas aeruginosa with manganous chloride

\begin{tabular}{|c|c|c|}
\hline Primary requirement & Growth also with & Symbol \\
\hline Tryptophan & Indole & $\mathbf{T}_{1}^{-}$ \\
\hline Tryptophan & • & $\mathrm{T}_{2}^{-}-$ \\
\hline Methionine & Homocysteine & $\mathbf{M}_{1}^{-}$ \\
\hline Methionine & Homocysteine, cysteine, cystine & $\mathrm{M}_{2}^{-}-$ \\
\hline Arginine & . & $\mathbf{A}^{-}$ \\
\hline Proline & • & $\mathbf{P}^{-}$ \\
\hline Isoleucine + valine & . & $I V_{1}^{-}, I V_{2}^{-*}$ \\
\hline Leucine & Isoleucine & $\mathbf{L I L}^{-}$ \\
\hline Lysine & - & $\mathbf{L}^{-}$ \\
\hline Histidine & . & $\mathbf{H}^{-}$ \\
\hline Threonine & . & Thr $^{-}$ \\
\hline Serine & . & $\mathrm{Se}^{-}$ \\
\hline Adenine & Hypoxanthine & $\mathbf{A d}^{-}$ \\
\hline
\end{tabular}

Double biochemical mutants were obtained by the method described above with appropriate addition of the required supplement of the primary mutant. Mutants resistant to certain antibiotics were also obtained. Streptomycinresistant mutants were obtained by plating heavy suspensions of bacteria on complete agar containing $250 \mu \mathrm{g}$. streptomycin $/ \mathrm{ml}$. Chloramphenicol-resistant mutants were obtained as single-step mutants by the gradient plate method of Szybalski \& Bryson (1952). Gradient plates were prepared with the upper layer containing $250 \mu \mathrm{g}$. chloramphenicol $/ \mathrm{ml}$. A culture was then streaked over each plate which, after overnight incubation, showed the characteristic pattern of confluent growth on one side extending to discrete colonies on the side of greatest antibiotic concentration; these latter colonies were picked off as chloramphenicol-resistant mutants.

Recombinants were tested for resistance or sensitivity to these antibiotics by streaking them on nutrient agar and using commercially prepared compressed tablets (Sentests; Evans Medical Supplies Ltd.) containing the appropriate antibiotic or by streaking a culture of the recombinant on complete agar incorporating the antibiotic. 


\section{Crossing procedure}

The method used for the detection of recombinants was that devised by Lederberg \& Tatum (1946) in which the parents (auxotrophs) have different biochemical deficiency markers and selection is made for the nutritionally non-exacting recombinant progeny (prototrophs). The details of the procedure are as follows. Each parent strain was grown separately overnight at $37^{\circ}$ on complete medium agar slopes. The growth was washed off in saline, centrifuged, washed twice in saline and then resuspended in saline to a concentration of $5 \times 10^{9}$ organisms $/ \mathrm{ml}$. Equal volumes of the two parent suspensions were then mixed and immediately plated out on the surface of a minimal agar plate in volumes of $0.2 \mathrm{ml}$./plate, the inoculum being spread uniformly over the surface of the plate with a bent glass rod. In all crosses a minimum of five plates of each parent alone was included as a control to detect and measure any back mutation to prototrophy.

To test recombinants further individual colonies were picked with a platinum needle and subcultured into tubes of liquid minimal medium. Such subcultures were slightly contaminated with the parent strains but not sufficiently to interfere with the tests for resistance to streptomycin or chloramphenicol. They were purified when required by streaking on nutrient agar and picking off single colonies.

\section{RESULTS}

A range of biochemical mutants was obtained for each of the four strains. Combinations of these mutants both within and between strains were chosen at random, and crosses made using the above procedure. It was found that with certain combinations prototrophic colonies appeared after $48 \mathrm{hr}$. while with other combinations no such colonies appeared; $72 \mathrm{hr}$. was subsequently taken as the incubation period for crosses and colony counts made after that length of time. It was found that some crosses produced more than 100 colonies/ $10^{9}$ parental organisms, other combinations produced fewer colonies while some produced none at all. The number of crosses made was extended and the results of these crosses are shown in Table 2. As a working hypothesis, the formation of prototrophs under these circumstances can be taken to mean that some type of genetic re-assortment is taking place. The results from Table 2 indicate that not all combinations of the mutant strains used were fertile. All crosses between mutants derived from the one parental strain failed to produce prototrophs, i.e. the strains used were self sterile. Certain interstrain combinations, viz. $1 \times \mathrm{L}, 1 \times 29,1 \times 3$ were clearly fertile. The combination $\mathrm{L} \times 29$ has given variable results for three crosses and negative results for the rest, while the combinations $\mathrm{L} \times 3$ and $29 \times 3$ did not produce prototrophs in any of the tested combinations. Within any one of the fertile combinations, not all the crosses produced prototrophs. For example, with the combination $1 \times \mathrm{L}$, $1\left(\mathrm{~T}_{1^{-}}\right)$produced prototrophs when crossed to $\mathrm{L}\left(\mathrm{IV}_{1}^{-}\right), \mathrm{L}\left(\mathrm{LIL}^{-}\right)$and $\mathrm{L}\left(\mathrm{Ad}^{-}\right)$ but not when crossed to $\mathbf{L}\left(\mathbf{T h r ^ { - }}\right), \mathbf{L}\left(\mathbf{T}_{1}^{-}\right)$or $\mathbf{L}\left(\mathbf{P}^{-}\right)$. Thus the particular 


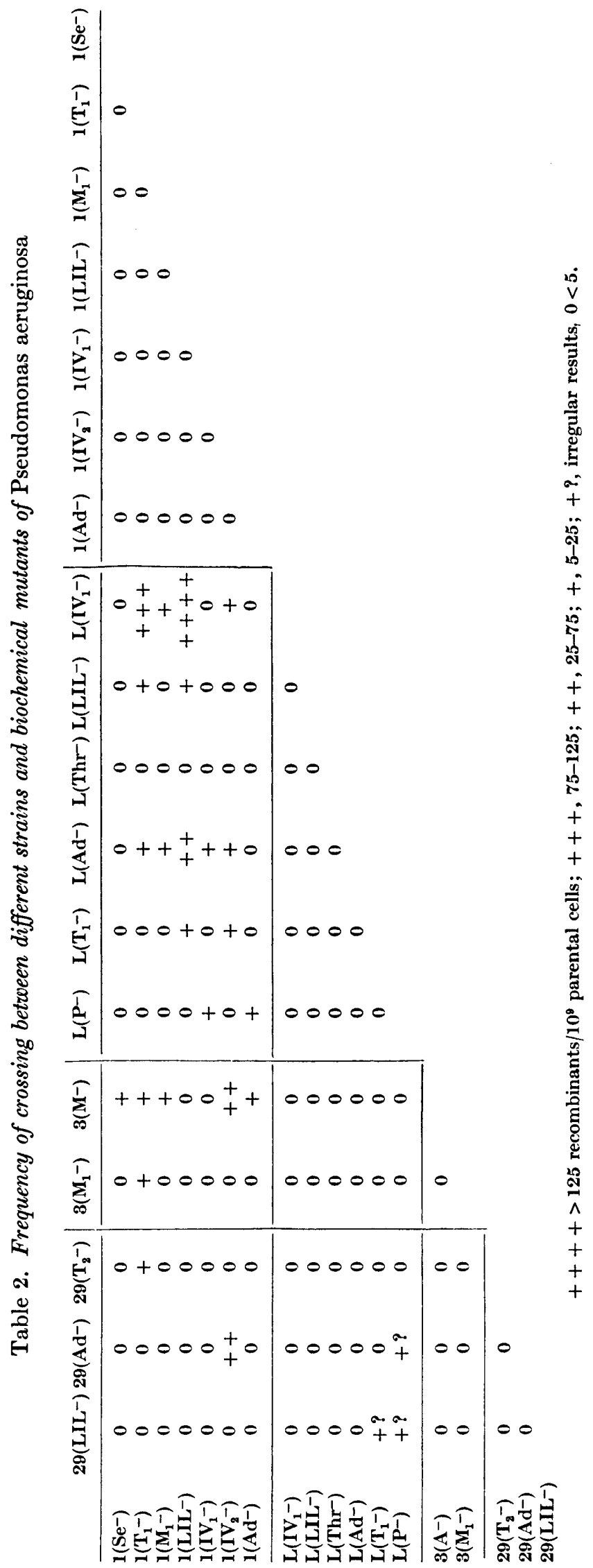


combination of biochemical mutant genes in any cross seems to determine whether or not prototroph formation will take place.

Double biochemical mutants were made for strains 1 and $\mathrm{L}$. The primary mutants used were $1\left(\mathrm{~T}_{1}^{-}\right), \mathbf{1}\left(\mathrm{M}_{1}^{-}\right), \mathbf{1}\left(\mathrm{LIL}^{-}\right), \mathrm{L}\left(\mathrm{IV}_{1}^{-}\right)$. The mutants obtained were $1\left(\mathrm{~T}_{1}-\mathrm{LIL}^{-}\right), \mathbf{1}\left(\mathrm{T}_{1}{ }^{-} \mathbf{A}^{-}\right), \mathbf{1}\left(\mathrm{M}_{1}{ }^{-} \mathbf{H}^{-}\right), \mathbf{1}\left(\mathrm{M}_{1}-\mathrm{T}_{1}^{-}\right), \mathbf{1}\left(\mathrm{LIL}^{-} \mathrm{T}_{1}^{-}\right), \mathbf{L}\left(\mathrm{IV}_{1}{ }^{-} \mathrm{L}^{-}\right)$, $\mathbf{L}\left(\mathrm{IV}_{1}-\mathrm{Se}^{-}\right), \mathbf{L}\left(\mathrm{IV}_{1}-\mathrm{T}_{1}^{-}\right)$. Crosses were made between double mutants of strains 1 and $L$ and in no case did the recombination frequency exceed 1 recombinant per $10^{9}$ parent cells. For that reason double mutants have not been used to any great extent.

Assuming that factor recombination is occurring in Pseudomonas aeruginosa, then this could result from a fusion mechanism similar to that in Escherichia coli, by a transforming principle as in the pneumococcus, by an infectious process as in salmonella, or through some previously unencountered mechanism. For several reasons the fusion mechanism is thought to be the most likely.

Experiments similar to those of Zinder \& Lederberg (1952) failed to produce or detect an FA principle. All experiments involving filtrates of cultures were in harmony with the conclusion that actual contact between the two parental organisms was needed for the formation of recombinants. The most critical of these experiments was a U-tube experiment as described by Davis (1950). The

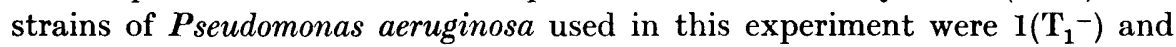
$\mathbf{3}\left(\mathbf{A}^{-}\right)$, and were known to form prototroph recombinants when grown together in nutrient broth. The two parental cultures were placed separately, one in each arm, of a U-tube separated at the bottom by a Corning UF sintered glass filter. They were grown for 5-6 hr. at $37^{\circ}$ with aeration. Then the culture medium was sucked from side to side through the sintered glass filter so that exchange of the culture fluids took place without mixing of the bacteria. This mixing of the culture fluids was continued for 4-5 hr. and then the culture incubated overnight. The cultures in each arm were then separately taken out, washed and plated. This experiment was repeated several times and in no case did recombination occur. As with Escherichia coli, this result suggests that actual contact of organisms was necessary for genetic recombination to take place.

The evidence against a transduction mechanism is supported by the fact that recombination for more than one genetic determinant occurred regularly. This was shown by studying the segregation of non-selective markers amongst the prototroph progeny. Two such markers were available, streptomycin resistance and chloramphenicol resistance. Accordingly, a number of crosses were examined, using those combinations of biochemical mutants and strains which gave sufficient numbers of prototrophs and observing the segregation of resistance and sensitivity to streptomycin and chloramphenicol amongst the prototroph progeny (Table 3). As it was necessary to obtain streptomycinresistant mutants of a number of biochemical-mutant strains, the allelism of these independent mutations to resistance was tested by means of crosses 10 , 11 and 12 in Table 3 , and the results show that all the occurrences of $\mathrm{S}^{\mathbf{r}}$ were allelic or else very close to one another. The results of crosses 1 to 9 indicate that the segregation of $S$ occurred amongst the prototroph progeny and that 
the relative numbers of $S^{r}$ and $S^{s}$ among the progeny depended upon the particular selective biochemical markers of the parents. The segregation of $\mathrm{C}$ is unusual in that most of the progeny resembled one parent with respect to this character. In crosses of the type $1 \times \mathrm{L}$ and $1 \times 3$ the progeny resembled the strain 1 parent. In the one cross of the type $1 \times 29$ which was examined the progeny resembled the strain 29 parent in their reaction to chloramphenicol. Because of these results allelism tests for the various occurrences of $\mathrm{Cr}^{\mathbf{r}}$ could not be carried out.

Table 3. Segregation of $\boldsymbol{S}$ (streptomycin) and $C$ (chloramphenicol) resistance in crosses between various biochemical mutants of Pseudomonas aeruginosa

\begin{tabular}{|c|c|c|c|c|c|}
\hline No. & Cross & $\mathbf{S}^{r} \mathbf{C}^{r}$ & $\mathrm{~S}^{8} \mathrm{C}^{\mathrm{r}}$ & $\mathrm{S}^{\mathrm{r}} \mathrm{C}^{\mathrm{s}}$ & $\mathrm{S}^{\mathrm{s}} \mathrm{C}^{\mathrm{s}}$ \\
\hline 1 & $1\left(\mathrm{~T}_{1}-\mathrm{S}^{\mathrm{r}} \mathrm{C}^{\mathrm{r}}\right) \times \mathrm{L}\left(\mathrm{IV}_{1}-\mathrm{S}^{\mathrm{s}} \mathrm{C}^{\mathrm{s}}\right)$ & 138 & 174 & 3 & 0 \\
\hline 2 & $1\left(\mathbf{T}_{1}-\mathbf{S}^{8} \mathbf{C}^{\mathrm{s}}\right) \times \mathrm{L}\left(\mathrm{IV}_{1}-\mathrm{S}^{\mathrm{r}} \mathbf{C}^{\mathrm{r}}\right)$ & 0 & 0 & 105 & 67 \\
\hline 3 & $1\left(L_{L} L^{-} S^{r} C^{r}\right) \times L\left(I V_{1}-S^{s} C^{s}\right)$ & 260 & 23 & 6 & o \\
\hline 4 & 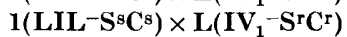 & 0 & 1 & 12 & 126 \\
\hline 5 & $1\left(L_{L L}-S^{r} C^{r}\right) \times L\left(T_{1}-S^{s} C^{a}\right)$ & 130 & 12 & $\mathbf{2}$ & 0 \\
\hline 6 & $\mathbf{l}\left(\mathrm{T}_{1}-\mathrm{S}^{\mathrm{r}} \mathbf{C}^{\mathrm{r}}\right) \times \mathbf{L}\left(\mathrm{Ad}^{-} \mathrm{S}^{\mathrm{s}} \mathrm{C}^{\mathrm{s}}\right)$ & 72 & 96 & o & 0 \\
\hline 7 & 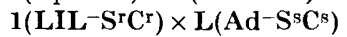 & 85 & 11 & 1 & 0 \\
\hline 8 & $\mathbf{I}\left(\mathrm{T}_{1}-\mathrm{S}^{\mathrm{s}} \mathrm{C}^{\mathrm{s}}\right) \times 3\left(\mathrm{~A}^{-} \mathrm{S}^{r} \mathrm{C}^{\mathrm{s}}\right)$ & . & . & 78 & 44 \\
\hline 9 & $1\left(\mathrm{~T}_{1}-\mathrm{S}^{\mathrm{r}} \mathrm{C}^{\mathrm{r}}\right) \times 29\left(\mathrm{~T}_{2}-\mathrm{S}^{s} \mathrm{C}^{\mathrm{s}}\right)$ & 0 & 0 & 19 & 80 \\
\hline 10 & $1\left(\mathbf{T}_{\mathbf{1}}-\mathrm{S}^{\mathrm{r}} \mathbf{C}^{\mathrm{r}}\right) \times 3\left(\mathrm{~A}^{-} \mathrm{S}^{\mathrm{r}} \mathrm{C}^{\mathrm{s}}\right)$ & 77 & 0 & 0 & $\mathbf{0}$ \\
\hline 11 & 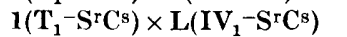 & . & . & 108 & 0 \\
\hline 12 & $1\left(L_{L}-S^{r} C^{s}\right) \times \mathbf{L}\left(I_{1}-S^{r} C^{s}\right)$ & . & . & 108 & $\mathbf{0}$ \\
\hline
\end{tabular}

Table 4. Segregation of $S, C, M_{1}$ and $T_{1}$ in progeny of the cross $\mathbf{1}\left(M_{1}-T_{1}-S^{s} C^{r}\right) \times L\left(I V_{1}-S^{r} C^{s}\right)$ plated on minimal medium, minimal + tryptophan or minimal + methionine

\begin{tabular}{|c|c|c|c|c|c|c|c|c|c|}
\hline \multicolumn{10}{|c|}{$1\left(M_{1}-T_{1}-S^{s} C^{r}\right) \times L\left(I V_{1}-S^{r} C^{8}\right)$} \\
\hline Medium & \multicolumn{2}{|c|}{$S^{r} C^{r}$} & \multicolumn{2}{|c|}{$\mathrm{S}^{\mathrm{r}} \mathrm{C}^{\mathrm{s}}$} & \multicolumn{2}{|c|}{$\mathrm{Ss}^{\mathrm{s}} \mathrm{r}$} & \multicolumn{2}{|c|}{$\mathrm{S}^{\mathrm{s}} \mathrm{C}^{\mathrm{s}}$} & Total \\
\hline \multirow{2}{*}{ Minimal } & \multicolumn{2}{|c|}{151} & \multicolumn{2}{|c|}{0} & \multicolumn{2}{|c|}{45} & \multicolumn{2}{|c|}{0} & 196 \\
\hline & $\mathbf{M}^{+}$ & $\mathbf{M}^{-}$ & $\mathbf{M}^{+}$ & $\mathbf{M}^{-}$ & $\mathbf{M}^{+}$ & $\mathbf{M}^{-}$ & $\mathbf{M}^{+}$ & $\mathbf{M}^{-}$ & \\
\hline Methionine & $\begin{array}{l}68 \\
\mathrm{~T}^{+}\end{array}$ & $\begin{array}{c}183 \\
T^{-}\end{array}$ & $\begin{array}{c}\mathbf{5} \\
\mathbf{T}^{+}\end{array}$ & $\begin{array}{c}\mathbf{2} \\
\mathbf{T}^{-}\end{array}$ & $\begin{array}{l}\mathbf{2 4} \\
\mathbf{T}^{+}\end{array}$ & $\begin{array}{c}181 \\
\mathrm{~T}^{-}\end{array}$ & $\begin{array}{c}\mathbf{2} \\
\mathbf{T}^{+}\end{array}$ & $\begin{array}{c}\mathbf{0} \\
\mathbf{T}-\end{array}$ & 465 \\
\hline 'Tryptophan & 41 & 5 & 7 & 0 & 10 & 207 & 0 & 0 & 270 \\
\hline
\end{tabular}

This lack of segregation has also been observed for the formation of pigment and for phage resistance. In crosses between strain 1 (pigmented, naturally resistant to phage 16 (Don \& van den Ende, 1950) and strain L (non-pigmented, susceptible to phage 16 ) the progeny were almost invariably pigmented and of nearly 500 recombinant prototrophs tested from various crosses all were resistant to phage 16 . The progeny of the cross $1\left(\mathrm{~T}_{1}-\mathrm{S}^{\mathrm{r}}\right)$ and $\mathrm{L}\left(\mathrm{IV}_{1}-\mathrm{S}^{\mathrm{s}}\right)$ were tested for their susceptibility or resistance to phages carried lysogenically by strains 1, 3 and 29 and for lysogenicity for strains 1, 3, 29 and $\mathrm{L}$. Of 144 recombinants all were susceptible to a phage carried by strain 3 and were themselves lysogenic for a phage which acted on strain L. In other words they behaved like the strain 1 parent. It is quite clear, however, that in the crosses 1 to 9 of Table $3, \mathrm{~S}$ has segregated frequently and $\mathrm{C}$ infrequently to result in novel genotypes. 
The segregation of non-selective biochemical markers was studied in the cross $\mathbf{l}\left(\mathbf{M}_{1}-\mathrm{T}_{1}-\mathrm{CrS}^{\mathrm{s}}\right) \times \mathrm{L}\left(\mathrm{IV}_{\mathbf{1}}-\mathrm{C}^{\mathrm{s}} \mathrm{S}^{\mathrm{r}}\right)$. The results of this cross are given in Table 4. It is clear that in minimal medium + methionine, $M_{1}$ has segregated to produce novel recombinants, and so has $T_{1}$ when the cross is plated on minimal medium + tryptophan. Lack of other suitable double-mutant stocks precluded further experiments of this type.

\section{DISCUSSION}

The described results lead to the conclusion that genetic recombination has occurred in Pseudomonas aeruginosa. The mechanism of this recombination is not clear however, and in view of the limited genetic data it would be unwise to speculate. It has not been possible to demonstrate any linear arrangement of the genes used. Even the allelism of certain biochemical markers is doubtful. The fertility patterns of the various mutants in the crosses shown in Table 2 have given some information concerning the allelic relationships of biochemical mutant genes used. For example, $\mathbf{1}\left(\mathrm{IV}_{\mathbf{2}^{-}}\right)$and $\mathbf{1}\left(\mathrm{IV}_{\mathbf{1}^{-}}\right)$have the same growth requirement, isoleucine + valine. Prototrophs are produced when $\mathbf{1}\left(\mathrm{IV}_{\mathbf{2}}{ }^{-}\right)$is combined with $\mathrm{L}\left(\mathrm{IV}_{\mathbf{1}^{-}}\right), \mathrm{L}\left(\mathrm{Ad}^{-}\right), \mathrm{L}\left(\mathrm{T}_{1}^{-}\right), 3\left(\mathrm{~A}^{-}\right)$and $29\left(\mathrm{Ad}^{-}\right)$, whereas $1\left(\mathrm{IV}_{1}^{-}\right)$ produces prototrophs only when combined with $\mathrm{L}\left(\mathrm{Ad}^{-}\right)$and $\mathrm{L}\left(\mathrm{P}^{-}\right)$so that it is unlikely that the isoleucine-valineless genes of each of these strains are allelic. In addition, as the combination $1\left(\mathrm{IV}_{2}^{-}\right) \times \mathrm{L}\left(\mathrm{IV}_{1}^{-}\right)$produces prototrophs the two isoleucine-valineless genes involved are also probably not allelic. It is not possible to say whether $\mathbf{l}\left(\mathrm{IV}_{1^{-}}\right)$and $\mathrm{L}\left(\mathrm{IV}_{1}^{-}\right)$are in fact allelic, although the evidence is consistent with this being so. In much the same way $1\left(\mathrm{~T}_{1}{ }^{-}\right)$and $\mathrm{L}\left(\mathrm{T}_{1}^{-}\right)$are probably allelic. They have the same growth requirements as each other (tryptophan, indole) and do not form prototrophs when crossed. It is curious, however, that the cross $1\left(\mathrm{~T}_{1}^{-}\right) \times \mathrm{L}\left(\mathrm{IV}_{1}^{-}\right)$produced prototrophs freely, whereas the cross $\mathrm{L}\left(\mathrm{T}_{1}^{-}\right) \times \mathbf{1}\left(\mathrm{IV}_{1^{-}}\right)$failed to do so.

These uncertainties, together with the rather anomalous segregation in crosses involving $1\left(\mathrm{LIL}^{-}\right)$where the proportions of $\mathrm{S}^{r} \mathrm{Cr}^{r}, \mathrm{~S}^{\mathrm{s}} \mathrm{Cr}^{\mathrm{r}}, \mathrm{Sr}^{\mathrm{r}} \mathrm{C}^{\mathrm{s}}$ and $\mathrm{S}^{\mathrm{s}} \mathrm{C}^{\mathrm{s}}$ were the same, whether $\mathbf{1}\left(\mathrm{LIL}^{-}\right)$was crossed to $\mathrm{L}\left(\mathrm{IV}_{\mathbf{1}}^{-}\right), \mathrm{L}\left(\mathrm{Ad}^{-}\right)$, or $\mathrm{L}\left(\mathrm{T}_{1}^{-}\right)$, make it unwise to draw any firm conclusion about linkage and gene order at this stage. Before such conclusions could be made the segregation of more genes would have to be studied. However from the non-random segregation of $\mathrm{S}$ in the various crosses studied it becomes likely that some system of ordered genes is operating.

A search has been made in Pseudomonas aeruginosa for a factor similar to the $\mathbf{F}$ factor in Escherichia coli. P. aeruginosa clearly differs from $\boldsymbol{E}$. coli in exhibiting self sterility. Such self sterility might indicate that strains were heterothallic and that the sexual differentiation is different from that of $E$. coli. It was found that the prototroph-forming capacity of $\boldsymbol{P}$. aeruginosa was completely destroyed by streptomycin, in contrast to the situation with E. coli (Hayes, 1952). Experiments similar to those carried out by Cavalli, Lederberg \& Lederberg (1953) in which the $\mathrm{F}^{+}$factor was readily transferred to $\mathrm{F}^{-}$cells were repeated with $\boldsymbol{P}$. aeruginosa, and yielded completely negative 
results. In short, fertility was not changed by any process of infection similar to that known to occur in $\boldsymbol{E}$. coli. However, differences in recombination ability were found to occur amongst the pseudomonad recombinants. From the cross $1\left(M_{1}-T_{1}-S^{s} C^{r}\right) \times L\left(I_{1}-S^{r} C^{s}\right)$ plated on tryptophan, recombinants were picked off and certain $\mathrm{T}^{-}$isolates were crossed to $1\left(\mathrm{LIL}^{-}\right)$and $\mathrm{L}\left(\mathrm{IV}_{1}{ }^{-}\right)$. Of 9 isolates tested 5 crossed with $\mathrm{I}\left(\mathrm{LIL}^{-}\right)$but not with $\mathrm{L}\left(\mathrm{IV}_{1}^{-}\right)$and the other 4 crossed with $\mathrm{L}\left(\mathrm{IV}_{1^{-}}\right)$but not with $\mathbf{1}\left(\mathrm{LIL}^{-}\right)$. The recombinants tested were all $\mathrm{Cr}^{\mathrm{r}}$ and in two cases the crosses with $\mathbf{1}\left(\mathrm{LIL}^{-}\right)$were analysed for segregation of $\mathrm{C}$. In each case $96 \%$ of the progeny were $\mathrm{C}^{\mathrm{s}}$, i.e. like $1\left(\mathrm{LIL}^{-}\right)$. This last result strongly suggests a change analogous to a change of polarity as occurs in $E$. coli (Hayes, 1953). Alternatively, perhaps, some factor or factors controlling the ability to cross with one or the other strain may be segregating.

Unexplained variations in recombination frequency have occurred during the course of these experiments, and preliminary studies have been made on factors affecting recombination frequency.

Certain strains have undergone spontaneous variation into various colonial types and the recombination frequency in certain tested crosses varies with these colonial types. The strain $\mathrm{L}\left(\mathrm{IV}_{1}-\mathrm{Sr}^{\mathrm{r}}\right)$ gave rise to two colonial types designated $\mathrm{L}\left(\mathrm{IV}_{1}-\mathrm{Sr}\right) \mathrm{t}$ (transparent) and $\mathrm{L}\left(\mathrm{IV}_{1}-\mathrm{Sr}\right)$ o (opaque). When each of these was crossed to $1\left(\mathrm{LIL}^{-}\right)$the recombination frequencies were $\mathrm{L}\left(\mathrm{IV}_{\mathbf{1}}-\mathrm{S}^{\mathrm{r}}\right) \mathbf{t}$ : 216, $\mathrm{L}\left(\mathrm{IV}_{1}-\mathrm{Sr}\right)_{0}$ : 4. The reason for such differences is not clear.

It has been found that the manner in which the cells are grown before being crossed affects the recombination frequency (recombinants $/ 10^{9}$ parental organisms). For the cross $1\left(\mathrm{~T}_{1}^{-}\right) \times \mathrm{L}\left(\mathrm{IV}_{1}{ }^{-}\right)$when the parental cells were grown under different conditions the recombination frequencies are as follows : (1) nonaerated broth, $30 ;(2)$ aerated broth, $51 ;(3)$ agar slopes, 146.

Other more subtle changes may take place. Cultures, which on first testing gave a certain recombination frequency, on subsequent testing in the usual manner failed to produce prototrophs at all, or in greatly diminished numbers. In some such cases crossing occurred when the parents were grown in aerated broth but not when grown on agar slopes. These changes have occurred in stocks kept at $4^{\circ}$. It will be recalled that the first detection by Hayes of the F- condition in Escherichia coli was with a stock kept at $4^{\circ}$, and it is possible that the changes referred to earlier may be due to changes in such fertility factors. It is interesting to note that an $\mathrm{F}^{-}$phenocopy was produced by Cavalli et al. (1953) when an $\mathrm{F}^{+}$culture was grown in aerated broth. So far it has not been possible to induce these changes in recombination frequency at will, and their occurrence has been too irregular to follow in detail.

I wish to thank Miss Jean Tolhurst, Alfred Hospital, Melbourne, Professor M. van den Ende, University of Capetown, South Africa, and Miss Nancy Atkinson, Department of Bacteriology, University of Adelaide, for providing the strains used in this work. I am grateful to Professor D. G. Catcheside for his helpful criticism of the manuscript. 


\section{REFERENCES}

Cavalli, L. L. \& Heslot, H. (1949). Recombination in bacteria: out-crossing Escherichia coli K-12. Nature, Lond. 164, 1057.

Cavalli, L. L., Lederberg, J. \& Lederberg, E. M. (1953). An infective factor controlling sex compatibility in Bacterium coli. J. gen. Microbiol. 8, 89.

Davis, B. D. (1948). Isolation of biochemically deficient mutants of bacteria by penicillin. J. Amer. Chem. Soc. 70, 4267.

Davis, B. D. (1950). Non-filtrability of the agents of genetic recombination in Escherichia coli. J. Bact. 60, 507.

DE HAAN, P. G. (1954). Genetic recombination in Escherichia coli B. 1. The transfer of the $\mathrm{F}$ agent to $E$. coli $\mathrm{B}$. Genetica, 27, 293.

Demerec, M. (1951). Mutagenic action of manganous chloride. Cold Spr. Harb. Symp. quant. Biol. 16, 215.

Don, P. A. \& van den Ende, M. (1950). A preliminary study of the bacteriophages of Pseudomonas aeruginosa. J. Hyg., Camb. 48, 196.

Hayes, W. (1952). Recombination in Bact. coli. K-12: unidirectional transfer of genetic material. Nature, Lond. 169, 118.

HAYES, W. (1953): The mechanism of genetic recombination in Escherichia coli. Cold. Spr. Harb. Symp. quant. Biol. 18, 75.

LEDERBERG, J. (1950). Isolation and characterization of biochemical mutants of bacteria. Methods in Medical Research, 3, 5.

Lederberg, J. (1951). Prevalence of Escherichia coli strains exhibiting genetic recombination. Science, 114, 68.

Lederberg, J. \& Lederberg, E. M. (1952). Replica plating and indirect selection of bacterial mutants. J. Bact. 63, 399.

Lederberg, J., Lederberg, E. M., Zinder, N. D. \& Lively, E. R. (1951). Recombination analysis of bacterial heredity. Cold. Spr. Harb. Symp. quant. Biol. $16,413$.

LeDERBerg, J. \& TATUM, E. L. (1946). Novel genotypes in mixed cultures of biochemical mutants of bacteria. Cold. Spr. Harb. Symp. quant. Biol. 11, 113.

Loutit, J. S. (1952). Studies on nutritionally deficient strains of Pseudomonas aeruginosa. I. The production by $\mathrm{X}$-rays and the isolation of nutritionally deficient strains. Aust. J. exp. Biol. Med. Sci. 30, 287.

Szybalski, W. \& Bryson, V. (1952). Genetic studies on microbial cross resistance to toxic agents. 1. Cross resistance of Escherichia coli to fifteen antibiotics. J. Bact. 64, 489.

Zinder, N. D. \& Lederberg, J. (1952). Genetic exchange in Salmonella. J. Bact. 64,679 . 